\title{
FERRAMENTAS DA QUALIDADE NA INDÚSTRIA METAL MECÂNICA: ESTUDO DE CASO DA APLICAÇÃO DO PROCEDIMENTO OPERACIONAL PADRÃO EM UMA EMPRESA DE USINAGEM
}

\section{ARTIGO ORIGINAL}

BARBOSA, Victor Hugo ${ }^{1}$

CARVALHO, Jaqueline Alessandra de ${ }^{2}$

SCHIMIDT, Willian Donizete ${ }^{3}$

ANJOS, Alexander Pitta dos ${ }^{4}$

BARBOSA, Victor Hugo. Et al. Ferramentas da qualidade na indústria metal mecânica: Estudo de caso da aplicação do Procedimento Operacional Padrão em uma empresa de usinagem. Revista Científica Multidisciplinar Núcleo do Conhecimento. Ano 05, Ed. 10, Vol. 20, pp. 36-58. Outubro de 2020. ISSN: 24480959, Link de acesso: https://www.nucleodoconhecimento.com.br/semcategoria/industria-metal

\section{RESUMO}

O ambiente em que as empresas estão inseridas vem apresentando mudanças cada vez mais complexas, buscando por condições cada vez maiores em termos de qualidade, custos menores e com foco na satisfação do cliente. Nesse contexto, no

\footnotetext{
${ }^{1}$ Estudando $010^{\circ}$ semestre de engenharia de Produção.

2 Estudando $010^{\circ}$ semestre de engenharia de Produção.

${ }^{3}$ Estudando $010^{\circ}$ semestre de engenharia de Produção.

4 Orientador. Mestrado profissional em Mestrado Profissional Engenharia de Produção. Especialização em Engenharia de Segurança do Trabalho. Graduação em Engenharia de Produção.
} 
qual as organizações do Brasil estão inseridas, para sobrevivência e sucesso nesse meio é necessária sua capacidade de atender as devidas exigências utilizando-se da inovação dos processos, a fim de elaborar uma vantagem competitiva e padronizada. O objetivo deste trabalho e alcançar a vantagem competitiva do mercado, com o foco na padronização e na implantação do Procedimento Operacional Padrão, utilizando ferramentas como PDCA e fluxograma. Esse projeto tem como estudo exploratórios de uma empresa metal mecânica, onde foram aplicados a organização das áreas de trabalho, execução de atividades ficaram mais claras e padronizadas, e a obtenção de seu resultado garantiu a melhor qualidade de seus serviços e produtos.

Palavras-chave: Padronização, PDCA, Procedimento Operacional Padrão, fluxograma.

\section{INTRODUÇÃO}

Para se manterem competitivas no mercado, as empresas precisam atualmente, criar alternativas para melhoria de processos e redução de custos.

De acordo com Dikesch e Mozzato (2004), a obrigação de satisfazer seus clientes e manter-se competitivo no mercado, necessita da sinergia de todos os setores da empresa para garantir a qualidade nas etapas do processo estabelecendo diferencial a concorrência gerando credibilidade e garantindo sobrevivência no mercado futuro.

No contexto industrial, é notória a aplicação de ferramentas de melhoria contínua, com o objetivo de aumento da produtividade e reduções de custo, para permanecerem competitivas no mercado.

Atualmente, existem várias ferramentas para serem utilizadas na melhoria da qualidade, estando disponíveis na maior parte das empresas que buscam melhoria em termos gerenciais, financeiros e produtivos (BUENO et al., 2015).

Olímpio et al. (2018) enfatizam que a eficiência e a eficácia dos processos produtivos estão ligadas diretamente à redução de custos como refugo e retrabalho, sendo que, 
desta forma, diante do contexto do mercado, uma das maneiras de atingir tais objetivos é aplicando melhorias nos processos.

De forma geral o método PDCA é uma ferramenta de solução de problemas e melhoria contínua, no qual as causas dos problemas são investigadas sob o ponto de vista dos fatos e a relação de causa e efeito é analisada em detalhes, resultando medidas planejadas para solucionar os problemas.

O presente trabalho se justifica em razão do objetivo da própria indústria objeto de pesquisa, por meio do estudo de caso em questão, uma vez que, ao término deste, espera-se a possibilidade da obtenção dos mesmos resultados relatados na literatura.

Como forma de contribuir para a literatura especifica da área, o objetivo desse trabalho consiste na detecção da causa raiz dos problemas encontrados nos processos produtivos, que contribuem para a geração de peças não conformes, utilizando das ferramentas de qualidade, propor melhorias no processo, a fim de reduzir o índice de perda de peças.

Das diversas ferramentas que vêm sendo desenvolvidas, em apoio ao aperfeiçoamento da gestão das organizações e métodos gerenciais, o método de gerenciamento de processos denominado PDCA, será foco do presente trabalho.

Para a elaboração da pesquisa partiu-se de uma revisão bibliográfica sobre o tema central (método PDCA) e tomou como base a aplicação dos conceitos estudados em um caso real em uma indústria metalúrgica de médio porte que atua no setor Metal Mecânico. A pesquisa caracterizada como um estudo de caso em uma empresa do interior do estado de São Paulo, é de natureza aplicada e cunho qualitativo e apresenta a implantação do método PDCA em toda área produtiva.

\section{REFERENCIAL TEÓRICO}

O modo de fazer as coisas, ou seja, a metodologia é melhorada, reciclada e atualizada inevitavelmente, pois àqueles que não se adequam às mudanças não sobrevivem ao

Disponível em: https://www.nucleodoconhecimento.com.br/engenharia-de-producao/industriametal 
mercado. Neste tópico abordaremos o referencial teórico que é base do nosso estudo e aplicação neste trabalho.

\subsection{ENGENHARIA E ORGANIZAÇÃO DO TRABALHO}

A engenharia e Organização do Trabalho tem como proposito, focar na produtividade e aumentar o rendimento da equipe, levando em conta a organização do trabalho sendo essencial para esses objetivos.

Segundo Fleury e Vargas (1983), os três pilares da Organização do trabalho, tem como base a Administração Cientifica (Fordismo e Taylorismo), os grupos semiautônomos e também o aumento de cargos. Dentre esses pilares também podemos incluir o famoso sistema Toyota de Produção, que é referência para empresas que buscam estruturação da padronização da produção.

O referencial teórico existente (ground theory) se resume à escola clássica e a sócio técnica. A orientação dos arranjos, podem ser considerados tradicionais que tem como inspiração arranjos considerados inovadores. Foi esta escola, por exemplo, que desenvolveu originalmente o conceito de organizações matriciais como forma de possibilitar uma adaptação a ambientes de trabalho mais dinâmicos e pouco afeitos à padronização rígida de procedimentos de trabalho, estabelecido nesse projeto como um documento chamado de procedimento operacional padrão. (BIAZZI, 1994).

\subsection{ESTUDO DE TEMPOS E MÉTODOS}

A divisão de operações possibilita retirar movimentos desnecessários e ainda simplificar, racionar ou conciliar os movimentos úteis proporcionando economia de tempos e esforço do operário. A partir disso, determina-se o tempo para execução das tarefas mediante o uso de um cronômetro. Meyers (1999) relata que Taylor foi a primeira pessoa a usar o cronômetro para estudar o trabalho e, portanto, é chamado 
"Pai do Estudo em Tempos e Métodos", com base nessa ferramenta, ela define seus parâmetros de forma lógica e coerente com o objetivo de racionalização do tempo.

Para Slack, Chambers, Harland, Harrison e Johnston (1996), no estudo de tempo é uma técnica de medida do trabalho que serve para registrar os tempos e o ritmo de trabalho de uma tarefa especializada, como também para analisar os dados obtidos, com a finalidade de se determinar o tempo necessário para a realização do trabalho com um nível de desempenho satisfatório.

Davenport (1994) conceitua um processo como uma ordenação específica das atividades de trabalho no tempo e no espaço, com um começo, um fim, inputs e outputs claramente identificados.

Segundo Taylor (1970), onde quer que se execute um trabalho manual é necessário que cada operário se especialize em sua etapa de produção, e a desenvolva da forma mais econômica e no menor período de tempo possível.

\subsection{QUALIDADE}

A abordagem de Falconi (1994) possui uma forte característica gerencial e tem como objetivo o planejamento, fluxo organizacional, responsabilidade gerencial. Por isso para qualidade é premissa básica em estabelecer metas e objetivos para melhorias.

Segundo Falconi (1994) qualidade possui duas definições:

1. Qualidade são aquelas características do produto que atendem as necessidades dos clientes e geram satisfação dos mesmos.

2. Qualidade consiste na ausência de deficiências.

Esse conceito ainda é usado hoje em dia, a norma ISO 9000:2005 que trata dos fundamentos e vocabulários do Sistema de Gestão da Qualidade, define no item 3.1.1 qualidades como sendo: o grau no qual um conjunto de características inerentes satisfaz a requisitos. 
O interesse em associar estas duas descrições de qualidade, resultou na simples definição de adequação ao uso. Apesar da falta de consenso entre as duas definições, desenvolveu seu enfoque para o conceito de satisfação para maximização dos interesses do cliente, pela avaliação da qualidade como. Concorda "adequação se, contudo, que interpretação ao uso" é sempre de que a qualidade deve ser considerada a partir do usuário.

Por outro lado, Deming (1990) define qualidade como o nível de satisfação dos clientes, propondo que a qualidade é construída e não apenas inspecionada.

Qualidade é a capacidade que um produto ou serviço tenha de sair conforme seu projeto. (PALADINI, 2009)

Para Falconi (1994), o produto que atende as necessidades de maneira perfeita, confiável e acessível, de forma segura no tempo certo e com qualidade, deve ser o foco que as empresas devem buscar.

Segundo Miguel (2001), para entendimento do que vem a ser qualidade, o importante é lembrar que sua definição não parte de uma ideia ou conceito absoluto, mas sim relativo a alguma coisa

\subsubsection{GESTÃO DA QUALIDADE TOTAL}

A partir da década de 50 , surgiu a preocupação com a gestão da qualidade, que trouxe uma nova filosofia gerencial com base no desenvolvimento e na aplicação de conceitos, métodos e técnicas adequadas a uma nova realidade. A gestão da qualidade total, como ficou conhecida essa nova filosofia gerencial, marcou o deslocamento da análise do produto ou serviço para a concepção de um sistema da qualidade. A qualidade deixou de ser um aspecto do produto e responsabilidade apenas de departamento específico, e passou a ser um problema da empresa, abrangendo, como tal, todos os aspectos de sua operação. (Revista Cientifica INTERMEIO, 2013, p. 93)

Os conceitos do TQC são aplicados pelos tópicos abaixo:

Disponível em: https://www.nucleodoconhecimento.com.br/engenharia-de-producao/industriametal 
- Orientação pelo cliente: Gera e elabora serviços e produtos que acabam sendo definitivamente requisitados para atender o consumidor.

- Qualidade está em primeiro lugar: Alcançar a sobrevivência por meio do lucro contínuo através da qualidade.

- Ações direcionadas pôr prioridades: analisar e apontar o problema, aquele que for o mais crítico, dar alta prioridade para solucioná-lo.

- Ação direcionada através de fatos e dados: discutir o raciocínio e decidir com base nas informações e fatos.

- Controle de processos: A empresa não deve manter seu foco somente em resultados, mas também no processo onde o resultado final pode nos mostrar ações corretivas.

- Controle da dispersão: Devemos cuidadosamente analisar os dados e com base nas informações e apontar a causa primordial da dispersão.

- O Próximo passo deverá ser seu cliente: O cliente deverá ser tratado como um rei ou até mesmo uma rainha, onde não se pode discutir, mas procurar atender os desejos. Não podendo passar produtos ou serviços com defeitos.

- Gestão de monte: A busca pela satisfação dos clientes tem como base exclusivamente focar em funções importantes. Devemos Identificar as verdadeiras necessidades dos clientes e com isso assegurar a maior qualidade do produto, prevendo as falhas com o devido padrão técnico.

- Ato de bloqueio: Deverá analisar os erros para que não os cometas novamente. Sempre procurar uma devida ação preventiva.

- Respeito com empregado: Sempre procurar a melhor forma de tratar os empregados, pois estão na linha de frente da produção de serviço ou produtos da sua empresa. Buscando treinamentos e padronização trará uma melhor qualidade nos processos da empresa.

- Compromisso de alto controle: Criando uma estratégia para a empresa, com uma meta a longo prazo para ter este auto controle.

A preocupação com a qualidade começou com Walter Andrew Shewhart, estatístico norte-americano que, já na década de 20 , tinha um grande questionamento com a 
qualidade e com a variabilidade encontrada na produção de bens e serviços. Shewhart desenvolveu um sistema de mensuração dessas variabilidades que ficou conhecido como Controle Estatístico de Processo (CEP). Criou também o Ciclo PDCA (Plan, Do, Check e Action), método essencial da gestão da qualidade, que ficou conhecido como Ciclo Deming da Qualidade. (JULIANA, 2009).

A seguir será apresentado o ciclo PDCA.

\subsection{PDCA}

O ciclo PDCA, que também pode ser denominado como Ciclo de Deming, é um processo de replicação que visa a promoção de melhoria contínua nas atividades que são submetidas a essa técnica. Na década de 20 foi idealizado por Walter Shewart e após a $2^{a}$ guerra, em 1950, difundida por Edward Deming. Vicente Falconi Campos foi quem difundiu no Brasil. Utilizou-se o PDCA no desenvolvimento e aplicação da Folha Padrão (F.P), com o propósito de controle e manter esse documento sempre utilizado, pois este é um documento vivo e necessita de reciclagem periódica para sempre se mostrar eficaz no seu objetivo de melhoria contínua. A Figura 1 apresenta uma ilustração do ciclo PDCA e suas etapas.

Figura 1 - PDCA 


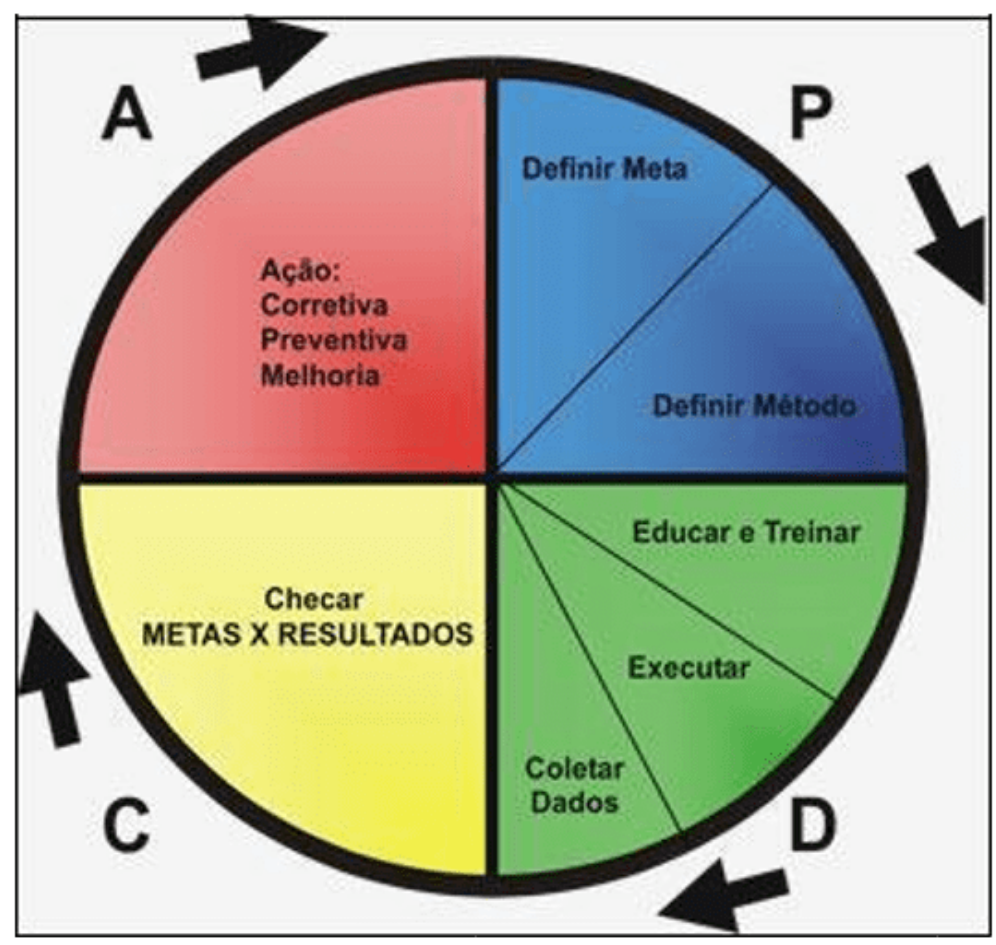

Fonte: Google

O ciclo PDCA é dividido basicamente em 4 etapas que descreveremos à seguir:

\section{Planejar}

Identificar suas características e causas através de um planejamento é uma forma muito eficaz na resolução dos problemas. A elaboração de plano de ação, objetivos executáveis e claros focados na obtenção de resultados positivos também.

\section{Executar}

As ações do plano de ação devem ser executadas, unindo-se à educação e treinamento de pessoal, juntamente com o acompanhamento do progresso da implementação.

\section{Controlar}


Medição, acompanhamento de indicadores, controle dos resultados são extremamente necessários, após a análise dos resultados fazer as reavaliações necessárias.

\section{$\underline{\text { Agir }}$}

Agir é necessário, caso a meta tenha sido alcançada, para que haja padronização das ações. Um "novo giro do PDCA" é necessário caso os resultados não tenham sido como esperados e o ideal é corrigir os erros

Para que o ciclo do PDCA aconteça é necessário o entendimento da padronização, descrito no tópico a seguir.

\subsection{PADRONIZAÇÃO}

Padronização (também conhecido como normalização) é o método que desenvolve e implementa as normas técnicas. Ela tem como principal objetivo identificar as especificações técnicas que aumentam a produtividade do produto ou serviço, que acabam aumentando a qualidade da empresa.

Segundo Scartezini (2009) a padronização surgiu depois da revolução industrial, onde os processos de fabricação e a mecanização, substituiu a forma que predominava antes, a artesanal. O aperfeiçoamento teve como foco no seu início no século XX, com base na padronização desenvolvida principalmente nas fábricas da Ford, que teve essencialmente dado atenção ao método da padronização do produto. Com a competividade bem disputada nos dias atuais a busca pela satisfação dos clientes, atendendo as suas necessidades e entregando produtos com qualidade vem a busca pela padronização dos serviços.

As etapas de padronização são basicamente:

- Determinação dos processos relacionados com os objetivos da organização.

- Ao definir o processo pergunte: 
1. Este processo é necessário?

2. Cada etapa do processo é necessária?

3. É possível simplificar?

4. É possível adotar novas tecnologias (informatização ou automação) no todo ou em parte?

- Treinamento dos responsáveis pela condução do processo de padronização.

- Elaboração dos primeiros procedimentos.

- Definição da sistemática de controle.

Segundo Saurin (1997) a padronização é uma excelente estratégia, que vem sendo disseminada desde o início dos movimentos de qualidade total na indústria, já explicado no tópico 2.2.1-Gestão da Qualidade Total. A origem do conceito de padronização dos métodos remonta à época da revolução industrial, onde surge a mecanização, em que a mesma acabou sendo idealizada e difundidas nas fábricas de automóveis (DUARTE, 2005).

\subsubsection{PROCESSOS}

Os processos estão presentes em todos os setores das organizações, seja ela de pequeno, médio ou grande porte. Não existe um produto ou serviço oferecido por uma empresa sem ter havido um processo, da mesma maneira que não existe um processo sem um produto ou serviço. (HARRINGTON, 1993).

De acordo com Scartezini (2009, p. 6), "logicamente, que utilizam os recursos da organização para gerar os resultados definidos, de forma a apoiar e definir os objetivos" processos, pode mostrar uma ideia melhor de como explicar o mapeamento de processos.

\subsubsection{MAPEAMENTO DE PROCESSOS}

Rother e Shook (2003), acabaram desenvolvendo uma ferramenta chamada Mapa de Fluxo de Valor que acaba sendo utilizada para obter informações relacionadas aos 
processos de fabricação. Mesmo tendo a sua aplicação voltada para fabricação, ele acaba se adaptando a vários segmentos.

Segundo De Melo (2008, p. 27), a escolha do mapeamento como ferramenta de melhoria se baseia em seus conceitos e técnicas que quando empregadas de forma correta, permite documentar todos os elementos que compõem um processo e corrigir qualquer um desses elementos que esteja com problemas sendo uma ferramenta que auxilia na detecção das atividades não agregadoras de valor. Para Rother e Shook (2000), o mapeamento é uma ferramenta que nos fornece uma figura de todo o processo de produção, incluindo atividades de valor e não agregadoras de valor. O mapeamento de processos se utiliza de diferentes técnicas de mapeamento que nos mostram diferentes enfoques sendo que a correta interpretação destas técnicas é fundamental durante esse processo. Tais técnicas podem ser utilizadas individualmente ou em conjunto dependendo do que se vai mapear. Para compreendermos o mapeamento de processos, primeiro é preciso discutir o conceito de qualidade. Foi a partir das avaliações de desempenho organizacional e da busca de aperfeiçoamento da qualidade que o mapeamento de processo se torna um instrumento necessário na gestão organizacional. (CUNHA, 2012, p. 11).

Outra ferramenta bastante usada no projeto e que auxiliou numa melhor interpretação, foi o fluxograma demonstrado no tópico a seguir.

\subsection{FLUXOGRAMA}

A opção do mapeamento como método de melhoria que acaba se baseando em suas convicções e técnicas quando aplicadas e empregadas de forma correta, possibilita documentar esses elementos que constitui-se em um processo e conserta qualquer um desses elementos que esteja com problemas sendo que a ferramenta que utilizamos na descoberta das atividades não gera valor agregado

Através do mapeamento de processos, será possível obter uma visão macro e micro das atividades como um todo.

Para Barnes (1997), o fluxograma é um processo visual utilizado para registrar procedimentos de uma maneira compacta, por meio de símbolos padronizados e assim possibilita a fácil compreensão e o entendimento.

Disponível em: https://www.nucleodoconhecimento.com.br/engenharia-de-producao/industria- 
Slack; Chambers e Johnston (2002), descrevem o fluxograma como uma ferramenta de mapeamento que mostra o fluxo real de trabalho fazendo com que seja possível o melhor registro de ações que serão aplicadas durante este processo de melhoria.

Para Scartezini (2009), a Composição dos fluxogramas exigem que algumas figuras façam parte elaboração dos mesmo, pois isso facilita com que as tarefas sejam padronizadas, evitando divergências, mas deve-se lembrar que cada empresa tem uma simbologia própria, e cada trabalhador deve saber esta simbologia, para não haver gargalos durante a execução de tarefa.

Com o presente estudo e utilização das ferramentas apresentadas, como o PDCA, a padronização e mapeamento de processos, fluxogramas, o estudo de tempos e métodos e o estudo da gestão da qualidade total, é possível iniciar a normalização dos processos e elaboração do procedimento operacional padrão, que será explicado no tópico a seguir.

\subsection{PROCEDIMENTO OPERACIONAL PADRÃO}

Com isso será permitido desenvolver um Procedimento Operacional Padrão (POP) que segundo Martins (2013), o procedimento operacional padrão orienta quem irá executar o trabalho, com isso o documento deve ser simples com o objetivo claro, o POP deve ser entendido por todos os funcionários da organização.

Procedimento Operacional Padrão (POP), Tem como objetivo ser um documento que possa descrever os procedimentos que cada trabalhador deverá cumprir na sua tarefa, com isso pode-se garantir uma padronização dos processos da empresa, garantindo uma melhor qualidade (DUARTE, 2005).

Para Martins (2013), o objetivo do POP, tem como foco sustentar o determinado processo, padronizando as operações evitando os desvios nas tarefas.

Não existe jeito certo ou errado de desenvolver um POP. Entretanto, existe vários tipos de POPs e para desenvolver o documento de acordo com a necessidade da

Disponível em: https://www.nucleodoconhecimento.com.br/engenharia-de-producao/industria$\underline{\text { metal }}$ 
empresa, deve-se escolher a opção mais adaptável à necessidade do processo, que seriam:

1. Lista de passos simples. Esta informação de procedimentos simples tende a ser curtos e de rotina. Neste documento também pode conter instruções de equipamentos de Proteção individual que os colaboradores terão que usar quando executarem as tarefas, assim evitando acidentes.

2. Lista estruturada de passos. Este formato é para procedimentos longos, ou seja, se ele tiver mais de dez passos se encaixa neste formato. Também pode ocorrer de os colaboradores terem de tomar decisões durante esses passos subsequentes

3. Fluxograma. Esta ferramenta é como se fosse um mapa com várias possibilidades, ou seja, tende a ser mais complexo dos que os formatos anteriores. Geralmente se opta por este formato se seus resultados nem sempre são previsíveis.

Segundo Lima (2005), o Procedimento Operacional Padrão é um documento de amostragem que acaba traduzindo o planejamento de trabalho, que irá ser executado trazendo detalhes específicos das tarefas que serão executadas com o objetivo de atingir a meta, onde a mesma deve conter inventário dos equipamentos; além de peças e materiais que serão utilizados com uma descrição específica dos procedimentos que serão realizados, possíveis anomalias, e criação de plano de ação para resolver esses problemas encontrados.

Procedimento operacional padrão para Lima (2005), tem como objetivo a busca pela normalização do processo ou atividade, ou seja, fazer com que pessoas que executam a mesma tarefa façam de forma inalterável, ou seja, qualquer pessoa treinada e apta a interpretar o POP irá exercer tal tarefa sempre mesma forma.

Existem dois fatores que devem ser levados em consideração antes de escrever o POP: 
1. Conhecimento antecipado do leitor. O mesmo tem que estar relacionado com a empresa e os demais procedimentos? A tecnologia e conhecida? Ou seja, a linguagem que será utilizada no POP tem que ter a mesma compreensão do leitor.

2. Suas habilidades linguísticas. Existe alguma chance de alguém que domina sua língua ler o seu POP? Caso isso seja possível, à inclusão de diagramas e imagens auxiliaram no entendimento do leitor.

Avalie seu conhecimento. Vamos responder as próximas questões: Você se considera qualificado para escrever um POP? Você sabe o que decorre desse processo? O que poderia dar errado? Como torná-lo seguro? Se você não capaz de responder a essas perguntas, pode ser melhor passar esta tarefa à outra pessoa. Se o POP for escrito, ou mesmo se não for claro, acabará resultando na improdutividade e assim gerando falhas no processo causando danos na qualidade do serviço ou produto e ainda trazendo riscos aos funcionários e ter impactos adversos em qualquer coisa - na equipe ao ambiente. Em resumo, não assuma esse risco (GOUREVITCH, 2008).

Se Ihe atribuíram esta tarefa e você se sente forçado (ou obrigado) procure pessoas que tenham esse conhecimento e peça ajuda. Fazer entrevistas é normal durante a criação de qualquer POP. Para garantir a descrição da informação correta e eficaz, é preciso ter paciência e humildade para não cometer erros graves.

O POP ou no caso a Folha de Processo (F.P.) é um documento que detalha todos os processos de transformação da peça bruta para peça acabada. É implantada para garantir que o processo seja sempre executado corretamente e que esteja sempre documentado, caso haja a necessidade de se treinar um novo colaborador.

Os procedimentos de transformação e alteração em metais e ligas metálicas, que utilizam essas peças em conjuntos mecânicos, acabam sendo numerosos e variados: pode-se fundir; soldar ou usinar o metal para obter a peça desejada. Vários fatores devem ser considerados ao escolher um processo de fabricação. Como exemplo:

- Forma e dimensão de cada peça;

$\mathrm{RC}: 62872$

Disponível em: https://www.nucleodoconhecimento.com.br/engenharia-de-producao/industriametal 
- Material a ser empregado e suas propriedades;

- Quantidade de peças a serem produzidas;

- Tolerância e acabamento superficial requerido;

- Custo total de processamento.

Os Processos de usinagem abrangem procedimentos de corte que acabam removendo esses excessos de material bruto, utilizando ferramentas para se obter uma peça que irá compor uma máquina de retífica.

As F.P. são utilizadas pelos funcionários do setor de usinagem que executam a atividade especificamente em tornos-CNC e/ou Centros-de-Usinagem. O encarregado do setor é responsável por supervisionar e controlar a aplicação da F.P., treinar e acompanhar o trabalho de cada operador de acordo com o documento. A F.P. também é utilizada para o alcance da meta de produção.

\section{ESTUDO DE CASO}

A empresa estudada está localizada na cidade de Sertãozinho, no Estado do São Paulo, Brasil. É uma indústria moderna, estruturada e sustentável, sempre priorizando a qualidade, inovação tecnológica e qualificação profissional.

A empresa é especializada em prestação de serviços de reparo em redutores de velocidades, utilizados nas mais variadas aplicações, como por exemplo: redutores de eixos paralelos aplicados em acionamentos mecânicos (bombas, picadores, niveladores, desfibradores, moendas, geradores, etc.), redutores planetários para acionamento de moendas em usinas de açúcar e etanol, multiplicadores de velocidade para acionamentos de aero geradores.

A empresa executa reparo em equipamentos dos mais variados fabricantes e com um escopo amplo de fornecimento, está apta ao fornecimento de peças de reposição, engenharia reversa, modernização, retrofit e etc. A mão-de-obra qualificada, é aplicada desde a solução de problemas em Campo, com a ida de técnicos à planta do cliente para identificação de possíveis problemas, até a vinda do equipamento à suas 
instalações, onde é desmontado, inspecionado e tem sua capacidade operacional reconstituída, de acordo com as normas vigentes e boas práticas de manutenção. A Figura 2 demonstra um Redutor enviado para manutenção.

Figura 2 - Redutor

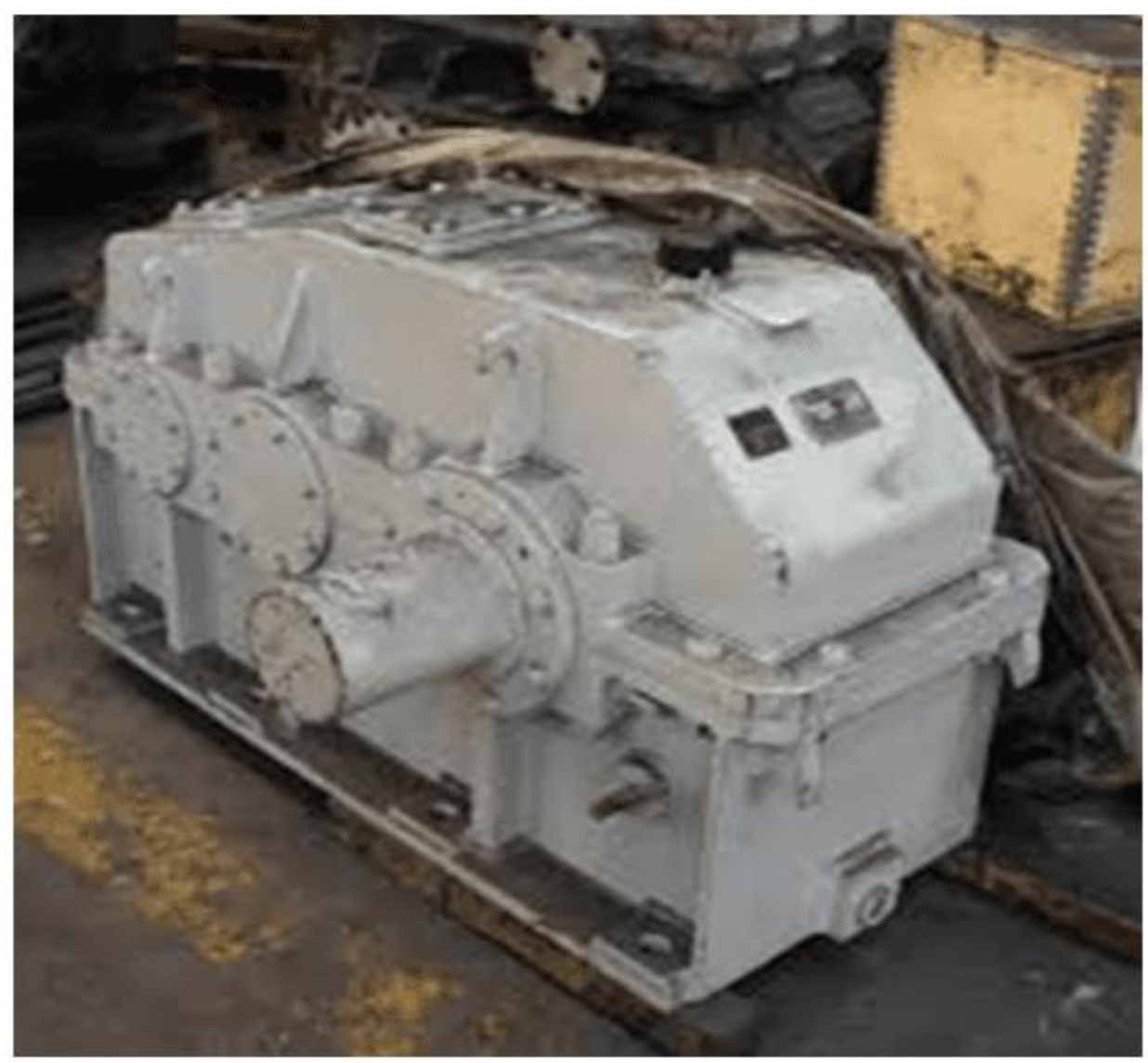

Fonte: $\mathrm{O}$ autor.

Com a crise que se instalou nos últimos anos, os serviços de reparo se tornaram opção recorrente nas mais diversas empresas, por ser mais atrativo financeiramente, e conseguir colocar os equipamentos em condições operacionais condizentes com as rotinas dos mesmos. Com os redutores de velocidade isso não seguiu um caminho diferente. Muito utilizados nas mais diversas plantas industriais, os equipamentos necessitam de reparos periodicamente, gerando assim o nicho de mercado que fez com que a empresa objeto de estudo surgisse e crescesse.

Disponível em: https://www.nucleodoconhecimento.com.br/engenharia-de-producao/industria$\underline{\text { metal }}$ 
Nos últimos tempos, o número de concorrentes tem crescido vertiginosamente, o que fez com a que a empresa buscasse adequações internas, para manter-se ativa no mercado.

É por conta deste mercado cada vez mais agressivo, que o intuito da empresa em aplicar os conceitos de melhoria contínua, no caso o PDCA, é minimizar os desperdícios oriundos de um mau planejamento de produção, organização de suas instalações, falta de mão-de-obra especializada e treinada, etc.

A empresa é distribuída em recepção, almoxarifado, setor de recursos humanos, setor de vendas, administração, financeiro, comercial, assistência, setor de usinagem, montagem, expedição e pintura.

O presente estudo foi realizado no setor de usinagem, que será caracterizado no tópico seguinte.

\subsection{PESQUISA-AÇÃO}

Conforme apresentado na metodologia, para o desenvolvimento do presente estudo, utilizou-se como técnica a pesquisa-ação. E para este processo os seguintes passos foram seguidos:

\subsection{FASE EXPLORATÓRIA}

Nesta etapa do processo, foram realizadas reuniões com a diretoria da empresa e engenheiros que apontaram que o setor de usinagem possuía uma série de problemas decorrentes aos processos produtivos, dentre eles, pode-se destacar: 
1. Defeitos: reflete-se quando alguma parte do processo de produção não atende qualidade exigidas. Portanto, como resultado, essa perda se concretiza na melhor forma de sobras ou retrabalho.

2. Processamento: Acaba ocorrendo no procedimento de atividades inúteis, ou até desnecessárias, com isso gera aumentos nos custos do processo do produto, ou serviço. Este tipo de aumento de gasto no processamento gera um desperdício, que se acaba percebendo somente quando mensura a produtividade

3. Superprodução: Usar os meios produtivos incorretamente, não distinguindo o necessário do excesso. Acontece no instante em que a empresa gera além das necessidades do próximo processo ou da sua realidade de mercado. Para muitos estudiosos essa pode ser considerada, mas das piores formas de desperdícios, pois contribui para a ocorrência de todas os outros desperdícios citados anteriormente.

A Figura 3 retratam bem a forma desorganizada de algumas partes do departamento de usinagem. A desorganização trazia consequências sérias, pois impactavam em diversos fatores como: falta de sequência de trabalho, desperdício de sobras de material, e até mesmo acidentes de trabalhos, para colaboradores que circulam por aquele local.

Figura 3 - Departamento de usinagem antes das aplicações da melhoria. 

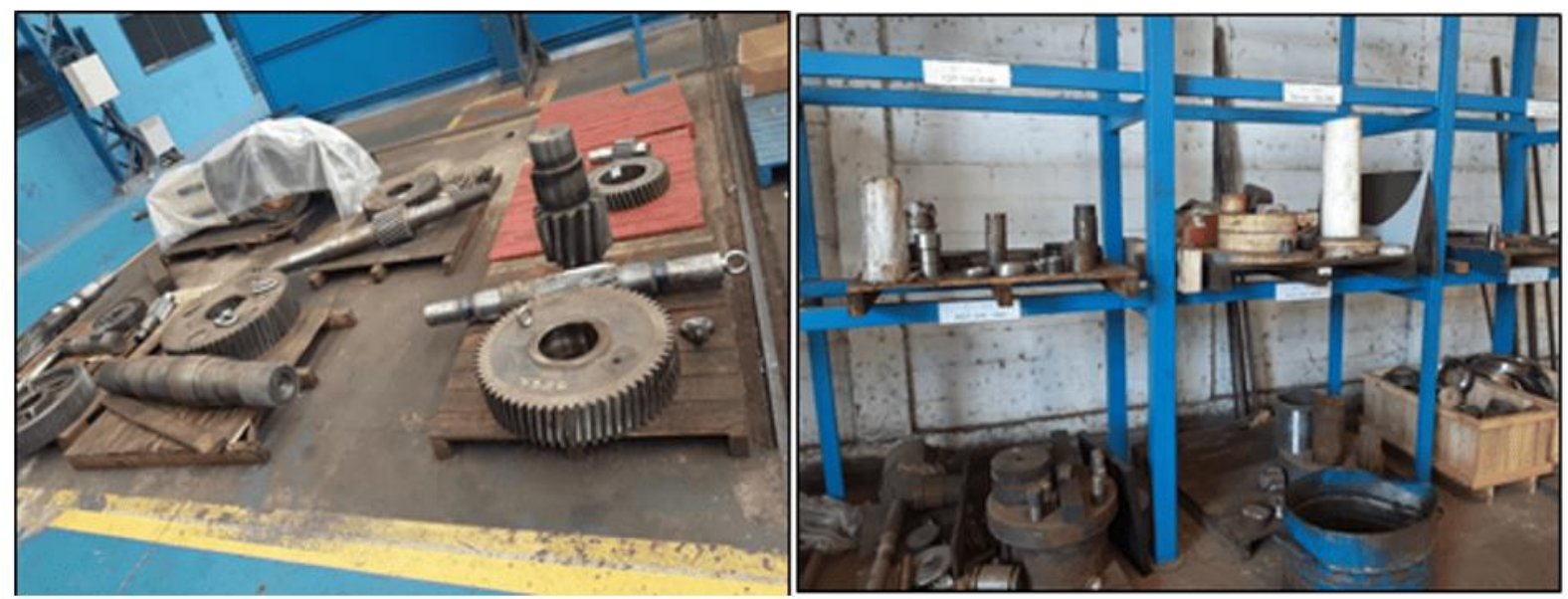

Fonte: $\mathrm{O}$ autor.

\subsection{PESQUISA APROFUNDADA}

Fase onde o autor do projeto entra em contato com os membros da organização e iniciam a identificação dos problemas, suas causas e prováveis ações a serem tomadas.

Nesta etapa, entrou em contato com a organização e o setor de usinagem onde o estudo será realizado.

Foi utilizado o PDCA como ferramenta de implantação, controle e revisão do documento procedimento operacional padrão.

\subsection{AÇÃO}

O que foi feito:

Período no qual com base na análise das fases anteriores procura-se ampliar os resultados, definir os objetivos a serem alcançados, estipular metas e prazos através de ações concretas e propostas de melhoria.

É a fase na qual o projeto está na prática aplicado moldado e estruturado para buscar suprir as necessidades definidas nos processos através da visão micro e macro da empresa.

$\mathrm{RC}: 62872$

Disponível em: https://www.nucleodoconhecimento.com.br/engenharia-de-producao/industria$\underline{\text { metal }}$ 
Com descrição do tipo de tarefa que cada pessoa deverá realizar em seu trabalho, deverá avaliar o procedimento de trabalho, que calcula seu tempo padrão e possa classificá-lo e com qual frequência é feito.

Todos esses procedimentos acabam proporcionando às empresas mais capacidade de acúmulo de valor ao negócio, com isso acaba gerando condições de trabalho melhores e reduzindo desperdícios realizando racionalização de processos.

\subsection{IMPLANTAÇÃO DA FOLHA DE PROCESSO NA VISÃO MACRO PELO PDCA}

Para implantação da F.P. na empresa, sugeriu-se que sua estruturação fosse realizada por meio do estudo do PDCA, visando maior eficiência e eficácia.

Inicialmente, o PDCA foi apresentado aos colaboradores envolvidos na formulação da proposta. Em seguida, foram requisitadas recomendações aos colaboradores na elaboração do Procedimento Operacional Padrão (ou seja, a referida F.P.) para sua correta padronização e aplicação.

Em seguida, o documento foi editado e revisado até que a aprovação do encarregado e do operador de máquina estivessem em consenso e de acordo com seu propósito de padronização. Feito isso, a F.P. é aplicada como instrução de trabalho padrão de um processo.

O PDCA aplicado no processo é mostrado a seguir:

P- Meta de Produção -Aumentar a produtividade de peças trabalhadas e redução de retrabalho e procedimentos desnecessários.

D- Folha de Processo -Implantação e treinamento da Folha de Processo; Execução da Folha de Processo. 
C- Verificação -Confirmação e Controle do efeito da Folha de Processo e sua eficiência, através de análises de gráficos e informações empíricas geradas em relatório.

A- Ação Corretiva -Analisar os resultados obtidos e comparar com os resultados que tinham sido planejados. Tomar ações para aplicar mudanças para melhorar o processo. (Girar o PDCA novamente).

A F.P. foi pensada em conjunto com os responsáveis pelo planejamento, engenharia, produção e controle de qualidade, otimizando dados e tornando as ações de fácil acesso tanto aos operados quanto aos responsáveis pelo controle da produção. A Figura 4 apresenta o modelo de F.P. utilizado:

Figura 4 - Modelo de F.P. aplicada nas melhorias da empresa.

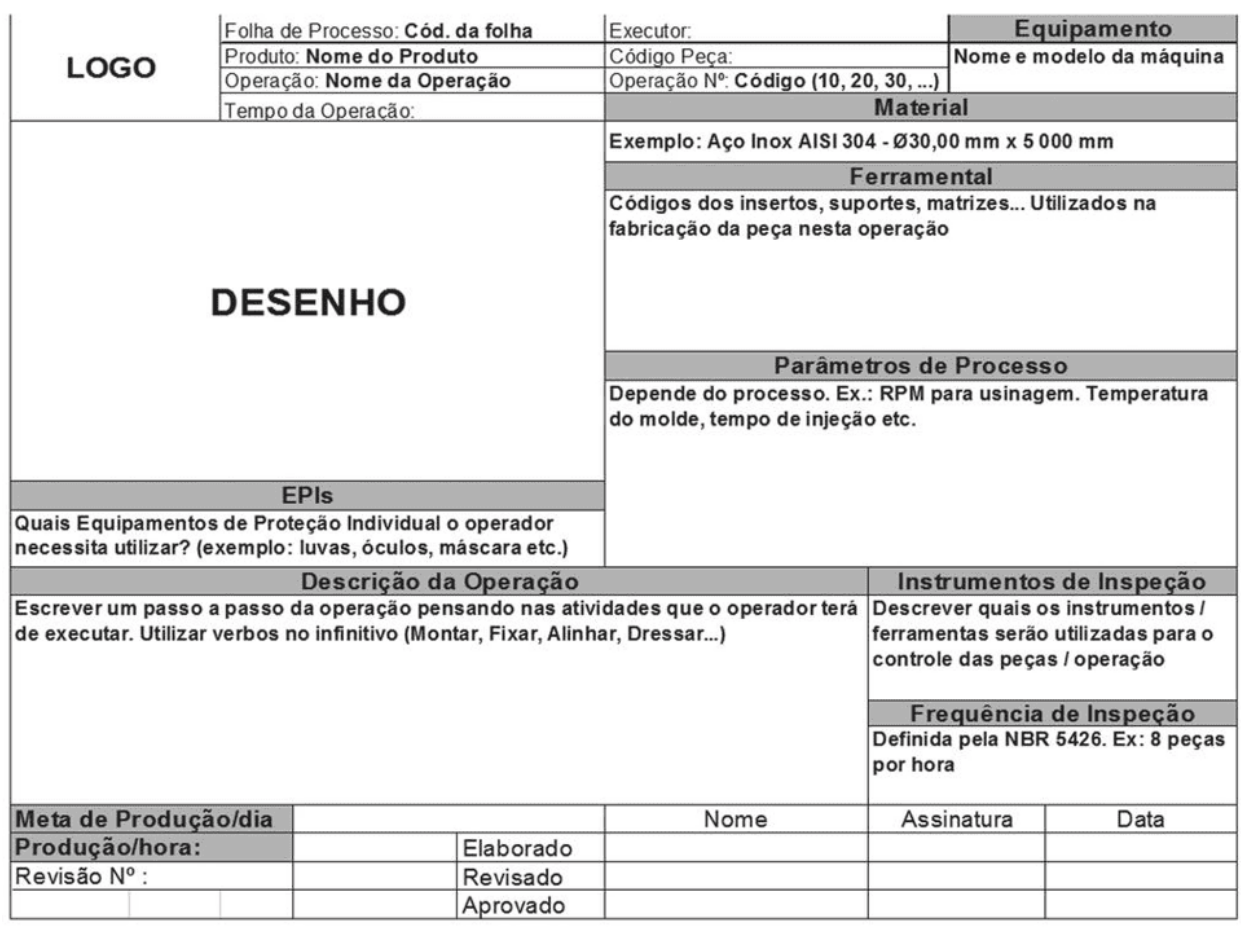

Fonte: $\mathrm{O}$ autor.

\subsection{RESULTADOS ESPERADOS}

RC: 62872

Disponível em: https://www.nucleodoconhecimento.com.br/engenharia-de-producao/industriametal 
- Definir a capacidade da fábrica;

- Reduzir o tempo de Setup das máquinas;

- Diminuir índice de refugo e retrabalho;

- Aumentar qualidade das peças;

- Evitar o desperdício de material;

- Evitar acidentes com colaboradores ao circular pelo departamento;

- Melhorar os prazos para entrega de equipamentos e componentes;

- Melhorar a eficácia e resultado da empresa.

A Empresa antes da implantação do projeto:

A empresa antes da elaboração e implantação da Folha de Processos executava as atividades de transformação e agregação de valor à peça em função do conhecimento, prévio ou adquirido, de cada operador, ou seja, não existia uma sequência padrão, tampouco um tempo padrão de cada etapa do processo. Logo, não era possível a mensuração da capacidade de produção do setor.

Após a implantação do projeto, eram esperados os seguintes resultados:

- Padronização e documentação das operações do setor de Usinagem;

- Definição da capacidade do setor de usinagem;

- Melhorias no desempenho dos funcionários;

- Diminuição do índice de retrabalho e de peças mortas.

Resultados alcançados até o momento (junho de 2020):

Análise dos números de F.P. segundo o mês de implantação:

Março - O número de F.P. elaboradas nesse mês foi de 16 , considerado abaixo da meta, pois o documento ainda estava em teste e necessitava de alterações.

Abril - O número de F.P. elaboradas nesse mês foi de 42, considerado satisfatório, levando-se em consideração a meta mensal, pois o documento já estava finalizado. 
Maio - O número de F.P. elaboradas nesse mês foi de 79 , considerado satisfatório levando-se em consideração uma nova meta mensal de 80 , pois a partir desse período houve a contratação de uma nova estagiária, dobrando assim a capacidade que até então existia.

Junho - O número de F.P. elaboradas nesse mês foi de 26 , considerado ruim levandose em consideração a nova meta mensal de 80 , pois apesar da nova contratação da estagiária, houve períodos de folga de ambos os estagiários.

Em síntese:

- Foram padronizadas e documentadas 200 operações do setor de Usinagem;

- Definiu-se a capacidade de operação de $31 \%$ do setor;

- Diminuiu o retrabalho em $44 \%$;

- Aumentou a produtividade em $50 \%$;

Concluímos que com a implantação do projeto, ou seja, padronizar os processos de fabricação do setor de usinagem da empresa, já mostrou um melhor aproveitamento dos tempos de produção, aumentando a produtividade e garantindo uma melhor qualidade das peças, apresentou também uma organização visual mais aparente do que deve ser feito em cada posto de trabalho aos olhos do encarregado pelo setor. Tudo isso foi possível devido ao mapeamento dos processos e posterior análise e revisão dos processos identificando os pontos críticos. Nesse trabalho houve uma motivação maior dos colaboradores, pois com os processos definidos e documentados para o operador, o ambiente se tornou mais confortável para o colaborador.

Por isso para que este projeto se mantenha útil para empresa, será preciso uma atualização contínua dos processos e sempre treinar as pessoas e verificar se os métodos ainda são válidos para a empresa.

\section{CONSIDERAÇÕES FINAIS}


O presente artigo teve como objetivo realizar o estudo de uma empresa metal mecânica, focado na padronização e na implementação do Procedimento Operacional Padrão, utilizando-se de ferramentas da qualidade. Os resultados esperados junto a empresa foram em sua maioria conquistados, tendo visto que é necessário um trabalho contínuo e novas atualizações dos métodos utilizados, moldando-se a realidade atual da empresa. Todas as análises, mapeamentos e estudos, juntamente com a participação dos colaboradores foram peças essenciais nesse processo.

\section{REFERÊNCIAS}

BARNES, R. M. Estudo de movimentos e de tempos: projeto e medida do trabalho. Trad. De S. L. O. Assis; J S. G. Azevedo e A. Pallotta. São Paulo: Edgar Blucher, 1997.

BARNES, R. M. Estudo de Movimentos e Tempos: Projeto de Medida de Trabalho. Primeira Edição. São Paulo: Edgard Blücher, 1963.

BIAZZI, F. O trabalho e as organizações na perspectiva sócio-técnica. Revista de Administração de Empresas, São Paulo, v. 34, n. 1, p. 30-37, jan./fev. 1994.

BLOG DA QUALIDADE. Procedimento Operacional Padrão (POP). Disponível em: <http://www.blogdaqualidade.com.br/procedimento-operacional-padrao-pop/>. Acesso em: 16 out 2020

BUENO, Marcos José Corrêa et al. Aplicação de ferramentas da qualidade na redução de custos e melhoria dos índices $\mathrm{cp}$ e cpk em uma metalúrgica. XXII SIMPEP: Simpósio de engenharia de produção, Bauru, Sp, p.1-12, 09 nov. 2015. Semanal.

CAMPOS, V. F, TQC - CONTROLE DA QUALIDADE TOTAL (No estilo japonês), Belo Horizonte/MG: 8ª edição-EDG ,1940

CICLO PDCA - https://sites.google.com/site/planejaweb/pdca - Acesso em 17 de julho de 2020. 
CUNHA, Alex. MAPEAMENTO DE PROCESSOS ORGANIZACIONAIS NA UnB: Caso Centro de Documentação da UnB - CEDOC. Bdm. Disponivel em: < https://bdm.unb.br/bitstream/10483/4191/1/2012_AlexUilamardoNascimentoCunha.p df >. Acesso em: 16 out 2020

DAVENPORT, T. Reengenharia de processos: como inovar na empresa através da tecnologia de informação. Rio de Janeiro: Campus, 1994.

DEMING, W. E. (1990) Qualidade: a revolução da administração. Rio de Janeiro: Marques Saraiva, 367 p. 47 , p. 164

DIKESCH, L. E .; MOZZATO, A. R. Gestão da produção: um estudo das indústrias do vestuário no Rio Grande do Sul. In: ENCONTRO DA ASSOCIAÇÃO NACIONAL DE PÓS-GRADUAÇÃO E PESQUISA EM ADMINISTRAÇÃO, 28., Curitiba, 2004. Anais... Rio de Janeiro: ANPAD, 2004.

DUARTE, R. L. Procedimento Operacional Padrão - A Importância de se padronizar tarefas nas BPLC. Curso de BPLC -Belém-PA/ 2005 8p.

FALCONI, Vicente Campos, TQC Controle da Qualidade Total (no estilo japonês). Fundação Cristiano Otoni, RJ, Bloch Editores, 1994.

FLEURY, A. C. C.; VARGAS, N. Organização do Trabalho. 1. ed. São Paulo: Atlas, 1983. $232 \mathrm{p}$.

GIL, Antonio Carlos. Métodos e técnica de pesquisa social. 6. Ed. São Paulo: 2008. p. 46.

GOUREVITCH, Philip. MORRIS, Errol. Procedimento operacional padrão: uma história de guerra. São Paulo: Companhia das Letras, 2008.

GUIMARÃES, Marina Cardoso. Proposta para implantação de gerenciamento de processos e da rotina em uma empresa de pequeno porte. Trabalho Acadêmico. Joinville: Universidade Estadual de Santa Catarina, 2011. 
HERBST, P. G. Autonomous groups functioning: exploration in behavior and theory management. London: Tavistock Publications, 1974.

HOPP, W. J.; SPEARMAN, M. L. To Pull or Not to Pull: What Is the Question? M\&SOM Manufacturing \& Service Operations Management, Vol. 6, No. 2, Spring 2004, pp. 133-148.

JULIANA A., 2009 - APLICAÇÃO DO MÉTODO QFD NO SETOR DE SERVIÇOS: ESTUDO DE CASO EM UM RESTAURANTE: JUIZ DE FORA, MG - BRASIL - MAIO DE 2009.

JUNIOR, Isnard Marshall; CIERCO, Agliberto Alves; ROCHA, Alexandre Varanda; MOTA, Edmarson Bacelar; LEUSIN, Sérgio. Gestão da Qualidade. 8aㅗ ed. Rio de Janeiro: Editora FGV, 2006.

MEYERS, F.E. -Motion and Time Study: for lean manufacturing -New Jersey $2^{\circ}$ edição, 1999.

MIGUEL, Paulo Augusto Cauchick -Qualidades Enfoques e Ferramentas, São Paulo: Artliber Editora, 2001

OLIMPIO, Rayton Matheus de Oliveira et. Al. Utilização das ferramentas da qualidade para melhoria de processo CNC: um estudo de caso. XXV SIMPEP: Simpósio de engenharia de produção, Bauru, Sp, p. 1-14, 09 nov. 2018.

PALADINI, Edson Pacheco -Gestão da Qualidade: Teoria e Prática/ Edison Pacheco Paladini. 2 ed. São Paulo: Atlas, 2009

Revista Científica INTERMEIO, faculdade de ensino e cultura do Ceará FACE/Faculdade de Fortaleza FAFOR-2013, http//www.fafor.edu.br/pesquisa/arquivos/Artigo_GESTA_DA_QUALIDADE.pdf Acesso em 10 de junho de 2020. 
ROTHER, M. \& SHOOK, J. Aprendendo a enxergar: mapeando o fluxo de valor para agregar valor e eliminar o desperdício. São Paulo : Lean Institute Brasil, 2003.

ROTHER, M; SHOOK, J.. Learning to See, The Lean Enterprise Institute, MA, USA, 2000.

SAURIN, T.A.; FORMOSO, T.C.; Planejamento de Canteiros de Obra e Gestão de Processos. Porto Alegra, 2006. Recomendações Técnicas HABITARE - Vol. 3; Programa de Tecnologia em Habitação.

SCARTEZINI, L. Análise e Melhoria de Processos, Goiânia: 2009. 54 p. Apostila.

SLACK, N.; CHAMBERS. S.; JOHNSTON. R. Administração da Produção. Trad. de M. T. C. de Oliveira, F. Alher. -2. Ed. São Paulo: Atlas, 2002.

SLACK, Nigel; CHAMBERS, Stuart; JOHNSTON, Robert. Administração da Produção. 2ª ed. São Paulo: Atlas, 2002.

TAYLOR, Frederick Winslow. Princípio de Administração Cientifica. São Paulo: Atlas, $7^{a}$ edição, 1970.

THIOLLENT, M. Pesquisa-ação nas organizações. São Paulo: Atlas, 1997.

Enviado: Setembro, 2020.

Aprovado: Outubro, 2020. 